\title{
ENTRE A ANTROPOLOGIA E A HISTÓRIA: ALGUNS PRESSUPOSTOS TEÓRICO-METODOLÓGICOS NO ESTUDO DAS RELIGIOSIDADES TERENA
}

\author{
Noêmia dos Santos Pereira Moura (UFGD \\ - noemiamoura87@gmail.com) \\ Rosalvo Ivarra Ortiz (UFGD \\ - rosalvortizms@gmail.com)
}

\begin{abstract}
Por várias vezes em lugares e momentos diferentes, grupos indígenas declararam ter "pacificado os brancos", arrogando para si a posição de sujeitos e não de vítimas. "Pacificar os brancos" significa várias coisas: situá-los, aos brancos e aos seus objetos, numa visão de mundo, esvaziá-los de sua agressividade, de sua malignidade, de sua letalidade, domesticá-los, em suma; mas também entrar em novas relações com eles e reproduzir-se como sociedade, desta vez não contra, e sim através deles, recrutá-los em suma para sua própria continuidade (CUNHA, 2002, APUD ALBERT \& RAMOS, 2002:7)
\end{abstract}

\begin{abstract}
Resumo: Neste artigo traçaremos parcialmente o caminho teórico-metodológico interdisciplinar percorrido na produção resultante dos estudos sobre religiosidades Terena desenvolvidos nos últimos anos. Para isso, faremos algumas considerações sobre conceitos e categorias utilizadas ao longo do texto para alicerçar nossas argumentações em torno da hipótese central - os Terena, principalmente as lideranças religiosas, apropriaram-se e terenizaram o cristianismo nas terras indígenas no Mato Grosso do Sul, a partir da Terra Indígena de Taunay-Ipegue. Dentre os vários enfoques destacados selecionamos como diretriz central a parte da epígrafe acima destacada, que retrata o protagonismo desses sujeitos históricos Terena em reproduzir-se como sociedade através dos religiosos não indígenas e de suas instituições cristãs, recrutando os brancos para sua própria continuidade. Nossa trajetória, portanto, será marcada pelos diálogos entre a Antropologia e a História.
\end{abstract}

Palavras-chave: diálogo interdisciplinar; antropologia e História; ReligiosidadesTerena.

Abstract: In this article we will outline the interdisciplinary theoretical-methodological path covered in the production resulting from the studies on Terena religiousness developed in recent years. For this, we will make some considerations about concepts and categories used throughout the text to support our arguments about the central hypothesis - the Terena, especially the religious leaders, appropriated and terenizaron the Christianity in the indigenous lands in Mato Grosso do Sul, the from the Taunay-Ipegue Indigenous Land. Among the several prominent approaches we selected as the central guideline the part of the abovementioned epigraph, which portrays the protagonism of these historical subjects Terena in reproducing as a society through non-indigenous religious and their Christian institutions, recruiting whites for their own continuity. Our trajectory, therefore, will be marked by the dialogues between Anthropology and History.

Keywords: interdisciplinary dialogue; anthropology and History; ReligiositiesTerena.

\section{INTRODUÇÃO}


As lideranças religiosas Terena cristãs - católicas, protestantes, protestante pentecostais, bem como as xamânicas - vão apropriar-se dos discursos, das práticas, das imagens, dos símbolos das agências religiosas cristãs para pensa-las e acomodá-las aos seus próprios termos e desígnios ao longo do século XX. É essa ação que vamos tentar realçar ao longo desta análise, enfatizando como se deu o diálogo entre a Antropologia e a História, nas linhas de Etnologia (OLIVEIRA, 1968) e História Indígena (MONTEIRO, 1994). Os Terena entraram em novas relações com os religiosos não indígenas e (re) produziram lideranças religiosas interna e externamente às terras indígenas. Nossa atenção voltou-se todo o tempo, no diálogo e concordância com as produções de Moura (2001; 2009), para perceber a consciência histórica e política que essa etnia vem desenvolvendo a partir do estreitamento de suas relações com a sociedade brasileira, na qual se encontram várias etnias conformando uma ampla diversidade cultural e pontuando seus traços adscritivos, numa perspectiva diacrônica, ao mesmo tempo em que mergulhamos no campo religioso atual, perpassado por várias relações sociais, politicas, cosmológicas, para evidenciar as atividades de cada grupo religioso. A conclusão, a qual chegamos, é de que as lideranças religiosas dessa etnia foram paulatinamente se apropriando das instituições eclesiásticas cristãs, ao mesmo tempo em que as amoldaram e acomodaram ao ethos Terena, produzindo a sua indigenização. A partir dessas instituições, os indígenas produziram novas relações sociais internas e externas que os habilitaram e capacitaram (empowerment) para ocupar espaços sócio-políticos internos e externos às suas Terras Indígenas. Para tanto, nos ancoramos em elaborações de antropólogos e historiadores no âmbito das Ciências Humanas para construirmos um corpus argumentativo e analítico que respaldasse a tese. E são esses pressupostos teórico-metodológicos que pretendemos trazer ao leitor.

No percurso procuramos nos desvencilhar de antigos conceitos e categorias que negaram a natureza histórica das populações indígenas, tais como aculturação, assimilação, resistência e colocamos em circulação outras, que pudessem dar visibilidade a agency dos interlocutores Terena. As novas categorias, tais como - apropriação, reforçamento identitário, protagonismo indígena, entre outras, estão sendo produzidas nessa relação dos pesquisadores com o campo da pesquisa. De acordo com Moniot (1988), Wolf (1982), Cunha (1992; 2002), Monteiro (1994) vamos reforçar a presença ativa dos Terena, promovendo e ampliando o diálogo entre a Antropologia e a História no sentido de qualificar a ação consciente deles enquanto sujeitos da história que seguem seu percurso desenvolvendo táticas e estratégias políticas, moldando o futuro diante dos desafios e das condições hegemônicas de contato e dominação. 
Por isso, entendemos que a configuração atual dos Terena tem que ser percebida como o resultado de vários séculos de contato com diversas etnias, em diversos espaços/temporalidades, das quais foram apreendendo elementos materiais e imateriais resultando no que são hoje - índios Terena cristãos (evangélicos, católicos) e xamânicos; incluídos nos espaços sócio-políticos brasileiros, sejam seculares ou religiosos; índios escolarizados, graduados e pós-graduados, que estão assumindo as negociações de suas demandas; índios aliançados interna e externamente as suas Terras Indígenas; índios guerreiros, que reivindicam a ampliação de suas áreas em litígio (MOURA, 2009).

\section{ETNOLOGIA INDÍGENA E HISTÓRIA INDÍGENA}

A Antropologia se constituiu enquanto área de conhecimento no século XIX a partir das realidades socioculturais da África, Oceania, Índia e América do Norte, trazidas à baila pelos estudiosos dos "povos exóticos”, os antropólogos. A América do Sul esteve às margens desse movimento sistemático de reflexão sobre as formas não europeias de vida social. Todos os seus temas e conceitos distintivos foram construídos no contato com as sociedades africanas, melanésias, asiáticas e norte-americanas. Temas como reciprocidade, totemismo, linhagens, exogamia, mana e tabu foram centrais nessas análises. As sociedades sul-americanas foram por muito tempo desconhecidas devido à inexistência de pesquisas e trabalhos acadêmicos. Segundo Viveiros de Castro \& Cunha (1993), como os conceitos da antropologia não se aplicavam bem a elas, resolviase o problema não as incluindo. Os sul-americanos se constituíram como índios fora da história, uma vez que os estudiosos pouco se referiram a eles. Em suas palavras: "Nenhuma monografia fundamental, nenhum ensaio teórico seminal se refere privilegiadamente aos índios das terras baixas sul-americanas, vítimas de uma espécie de indiferença antropológica" (VIVEIROS DE CASTRO \& CUNHA, 1993: 10-11).

Lévi-Strauss (1975) foi considerado, pelos autores citados acima, como o primeiro grande teórico a trazer à cena as sociedades sul-americanas. Todavia, os efeitos de tais mudanças só vieram a atingir uma massa crítica a partir da década de 1980. Cabe ressaltar que essa massa crítica está centrada em sua grande parte nos estudos de Etnologia e História Indígena da Amazônia, ficando 
ainda descoberta uma grande área habitada por várias populações indígenas. Todavia, na tentativa de construir trabalhos monográficos de qualidade, alguns pesquisadores no Brasil, quadro no qual pretendemos nos encaixar, estão, recentemente, tal como recente é a reviravolta produzida pelos grupos de estudos sobre cultura, religiões e religiosidades, desenvolvendo suas pesquisas acadêmicas em programas de Mestrado e Doutorado.

A tendência Novo Americanismo, assim denominada por Viveiros de Castro \& Cunha (1993), ganhou ímpeto ao final dos anos setenta do século passado. Os etnólogos da Amazônia e do Brasil Central começaram a elaborar, naquela época, uma problemática própria, guiados por seus trabalhos de campo. Nessa nova perspectiva, alguns termos clássicos como mudança social, aculturação, contato interétnico, foram sendo abandonados ou revistos criticamente, pois apontavam para uma ausência de estrutura nos processos de interação de sociedades (idem: 11). A lógica interna e o papel essencialmente ativo e criador das sociedades ameríndias na sua confrontação com as estruturas sócio-políticas, de origem europeia (poderes coloniais, sociedades nacionais), atualmente estão orientando a produção acadêmica e novos conceitos estão sendo produzidos. Seja mostrando a dialética tradição/invenção que sustenta a reprodução cultural dessas sociedades (TURNER, 1993), seja analisando seus modos cognitivos e simbólicos de elaboração da historicidade (FRANCHETTO, 1993; FRANCHETTO \& HECKENBEGER, 2001).

Dois artigos foram ao mesmo tempo a delimitação de uma nova etnologia das terras baixas sul americanas e uma elaboração do estruturalismo levistraussiano e, por isso, são merecedores de especial destaque: o artigo "A construção da pessoa nas sociedades indígenas brasileiras" de Seeger, Da Matta e Viveiros de Castro (1979) e "Os pronomes cosmológicos e o perspectivismo ameríndio" de Eduardo Viveiros de Castro (1996). A importância das noções de pessoa e corporalidade foram salientadas no final da década de 1970 pelos autores acima destacados. A ideia de construção processual da pessoa desenvolveu novos conceitos atuais como body, self, agency e embodiment, empowerment, entre outros, que nos auxiliam a repensar e questionar dualismos clássicos na Antropologia, tais como: indivíduo/sociedade, natureza/cultura, corpo/alma.

O perspectivismo ameríndio, por sua vez, é um conceito que podemos destacar como delimitador de um novo pensamento etnológico brasileiro. Em uma entrevista, publicada no artigo “A Inconstância da Alma Selvagem”, Viveiros de Castro (2002) define o perspectivismo da seguinte forma: 
(...) uma concepção segundo a qual as diferentes subjetividades que povoam o universo são dotadas de pontos de vista radicalmente distintos (...) sustenta que a visão que os humanos têm de si mesmos é diferente daquela que os animais têm dos humanos, e que a visão que os animais têm de si mesmos é diferente da visão que os humanos têm deles. Os jaguares nos veem como pecari, os pecaris nos vêem como jaguares (ou como espíritos canibais); mas os jaguares e os pecaris, cada qual por seu lado, vêem-se como gente, e vêem seu comportamento como cultural: o sangue que o jaguar bebe é sua cerveja de milho, a lama onde chafurdam os pecaris é sua casa cerimonial, e assim por diante (VIVEIROS DE CASTRO, 2002:467-8).

Faz-se oportuno destacar que essa definição é significativa para entendermos as relações do xamã Terena com o mundo dos espíritos e o respeito que tem pelo mundo dos animais e das plantas. A atividade xamânica consiste no diálogo/tradução do xamã entre os mundos habitados por várias espécies naturais. Somente ele tem condições de passar de um mundo ao outro, conforme a tese de Viveiros de Castro. O autor afirma que os xamãs são diplomatas que realizam a interlocução no diálogo interespécies.

(...) é preciso que ele passe de um ponto de vista a outro, que se transforme em animal para que possa transformar o animal em humano e reciprocamente. (...) o xamã é ao mesmo tempo o sacrificador e a vítima. Ele realiza em si mesmo, em sua própria pessoa - corpo e alma -, a conexão sacrificial entre humanos e não humanos. É o próprio xamã que atravessa para o outro lado do espelho; ele não manda delegados ou representantes (Idem, p. 469).

Os antropólogos têm se esforçado bastante para aprofundar os estudos das populações ameríndias. Entretanto, os estudos desenvolvidos na América do Sul relacionados a povos indígenas fora da área da Amazônia e do Brasil Central carecem de mais aprofundamento teórico e de uma maior abrangência. As novas gerações de antropólogos estão desenvolvendo essa tarefa, pelo que podemos perceber a partir das publicações recentes dos programas de pós-graduação em Antropologia.

A História, por sua vez, no desenvolvimento da História Indígena, tem dialogado continuadamente com a Antropologia, a Sociologia, a Geografia, a Linguística e a Arqueologia, mas só muito recentemente, no século $\mathrm{XX}$, incluiu os povos indígenas enquanto sujeitos históricos (WOLF, 1982; MONIOT, 1988; MONTEIRO, 1994; ALMEIDA, 2003). Pensar a alteridade e investigá-la nas suas mais diversas faces e temporalidades tem sido uma conquista da História Cultural. Foi especialmente através de sua abordagem que o Outro se configurou como tema de estudo, resultando, muitas vezes, em revisões históricas. 
No caso da História do Brasil, pesquisar populações indígenas abriu searas fundamentais voltadas aos estudos sobre os escravos africanos e os indígenas e, como resultado, uma 'outra' história tem sido construída, se distanciando da história oficial, pois as considerações de novos sujeitos exige uma compreensão diversa das circunstâncias históricas.

As análises recentes buscam ancoragem nas produções desenvolvidas acerca da Amazônia, uma vez que os etnólogos e historiadores indígenas, expoentes no Brasil, estão voltados para os povos indígenas amazônicos ou de outros países (VIVEIROS DE CASTRO \& CUNHA, 1993; VIVEIROS DE CASTRO, 2002; CUNHA, 1992; ALBERT \& RAMOS, 2002; FRANCHETTO \& HECKENBERGER, 2001; WRIGHT, 1999; MONTERO, 2006). Em sua maioria, as pesquisas são marcadas por uma leitura interdisciplinar e crítica, a partir da qual se constituem novos conceitos, tais como tradução, apropriação, ressignificação, socialidade, empowerment, todos vinculados a um contínuo movimento das populações indígenas.

Cunha (1992) afirma que somente os indígenas vindos de suas diversas etnias para as universidades poderiam produzir uma história de fato indígena. $\mathrm{Na}$ introdução de "História dos Índios no Brasil", descreve a narrativa da escolha realizada pelos Krahô, que preferiram o arco e a cuia à espingarda e ao prato, que foram entregues aos "brancos". Para os nativos, segundo a explicação dos Krahô, foram dadas as mesmas opções que aos demais. A escolha feita, em muitos casos foi equivocada, segundo suas leituras mais contemporâneas. A autora capta a percepção indígena: "é que a opção, no mito, foi oferecida aos índios, que não são vítimas de uma fatalidade, mas agentes de seu destino. Talvez escolheram mal. Mas fica salva a dignidade de terem moldado a própria história” (CUNHA, 1992:19).

A chave do extermínio, presente na tese evolucionista, portanto, volta-se para a impossibilidade do indígena produzir história. Essa imagem inanimada do indígena - “fósseis vivos" - cuja selvageria esterilizava os germes da curiosidade histórica, cristalizou-se na famosa frase de Varnhagen registrada no século XIX, “de tais povos na infância não há história: há só etnografia” (CUNHA, 1992:30). Pensar como Cunha (1992), que os povos indígenas fizeram escolhas, é dar ouvido às sociedades indígenas para que reconstruam suas histórias do mundo a partir de seus próprios termos, sabendo que suas escolhas tinham e têm consequências. É aceitar que ao longo do processo histórico, marcado pelas relações entre índios e não índios, os primeiros estiveram "pacificando o branco", como bem demonstraram Albert \& Ramos (2002). Desta forma, 
as ações indígenas são qualificadas como conscientes e esses povos, sujeitos com história, desenvolvedores de táticas e estratégias políticas, que produziram e continuam produzindo seu futuro, mesmo que em circunstâncias mediadas pelo contato irreversível e pela dominação. Contudo, essas novas posturas teórico-metodológicas, em construção, seguem marcadas por muitos desafios.

O primeiro, talvez, seja o de desconstruir essas imagens sedimentadas ao longo de dois séculos. A História Cultural conduz os historiadores a refletir sobre o produto da pesquisa como uma construção de representações acerca dos seus mais variados objetos. Novos objetos suscitam novas fontes e, portanto, novos conceitos e categorias que os alicercem. Há, portanto, no contexto atual, a necessidade de um dinâmico diálogo entre historiadores e antropólogos. As reflexões em marcha demandam novas abordagens e novas fontes. Surge, portanto, uma nova bibliografia, principalmente a partir das décadas de 1980-90, que amplia a visibilidade de povos indígenas numa história que sempre os omitiu e que revela as perspectivas desses mesmos povos sobre seu próprio passado, incluindo versões alternativas do contato e da conquista (MONTEIRO, 1994; ALMEIDA, 2003; ALBERT \& RAMOS, 2002; WRIGHT, 1999; 2004).

A nova produção serve de instrumento para os estudiosos e para os indígenas, que atuam nos movimentos indigenistas e indígenas, defendendo e reivindicando a materialização dos direitos adquiridos. O Outro (Alter) sempre teve um status marginal e menor, isso quando não fora segregado e invisibilizado pelas sociedades que se consideravam e continuam se considerando civilizadas. Reconhecê-lo é ao mesmo tempo reconhecer um $e u$ provocador do medo, da segregação e da exclusão (MOURA, 2009).

\section{ANTROPOLOGIA, HISTÓRIA, RELIGIÃO E POVOS INDÍGENAS}

O Grupo de Pesquisa no Brasil, que nos remeteu ao estudo sobre missões religiosas e povos indígenas, foi constituído pelos pesquisadores Aparecida Vilaça e Robin M. Wright, no ano de 1994, na reunião da Associação Brasileira de Antropologia, realizada em Niterói. Esse fórum, segundo Robin Wright (1999), foi o ponto de culminância para a consolidação do primeiro volume de “Transformando os Deuses: os múltiplos sentidos da conversão entre povos indígenas no Brasil”, 
dedicado aos estudos sobre os povos na Amazônia. O segundo (2004) ampliou o leque para outras regiões, inclusive abrangendo os Terena. Os dois últimos seguiram com a mesma abrangência.

Os textos contidos em "Transformando os Deuses" ajudaram na reflexão sobre a abordagem que daríamos ao encontro entre os missionários norte-americanos e os Terena. Acessamos trabalhos já concluídos em outros programas na busca de subsídios teórico-metodológicos. Nossos anseios, por um novo debate, foram inicialmente contemplados com as contribuições suscitadas no âmbito do núcleo de pesquisa supracitado. No bojo da crítica aos trabalhos ideologicamente vinculados ou afetados por uma concepção aculturativa e assimilacionista pretendíamos nos distanciar de uma análise das consequências e impactos das práticas missionárias na cultura Terena, ligada às mudanças culturais (ALTENFELDER SILVA, 1948; OLIVEIRA, 1968, 1976). Almejávamos ir além, na intenção de perceber como as populações indígenas interpretaram as ações missionárias e quais as estratégias desencadeadas por elas em suas relações com as agências religiosas.

Percebemos que os Terena não reagiam meramente, eles agiam criativamente e nos forneciam abundantes provas de que eram sujeitos ativos no processo de constituição e conformação das novas situações propostas para eles. Para tanto, fomos a campo levantar os dados para comprovarmos nossas hipóteses e conformar nossa tese, além de nos debruçarmos sobre as novas publicações que suscitavam essa leitura. Foi nessa busca por novas abordagens que nos deparamos com os autores acima destacados, no campo da antropologia, da sociologia e da história (MOURA, 2009). Abriu-se para nós a possibilidade de apontar as perspectivas dos indígenas sem neutralizar a perspectiva dos missionários.

O conceito de "campo religioso", formulado por Bourdieu (2003), em sua obra "O Poder Simbólico", esteve perpassando toda nossa análise. O campo religioso foi colocado como um espaço social de relações objetivas no qual cada agente teve/tem sua posição demarcada e por isso, a cada estratégia de operação, entra em relação direta com outros agentes, produzindo uma nova reconfiguração posicional e a recomposição do campo. Portanto, um espaço perpassado por conflitos, concorrências e desigualdades de forças.

Nós percebemos esses conflitos, mas estávamos voltados a apreender as táticas das lideranças Terena para canalizá-los em seu favor, produzindo o que denominamos empowerment: o modo como os indígenas se movimentam nesse campo, apropriam-se dos discursos e práticas dos variados agentes e se reposicionam capitalizados, para assumir sua liderança, seja entre os católicos ou entre 
os evangélicos. Ou seja, evidenciar como as lideranças indígenas "englobam a ordem global em suas próprias ordens cosmológicas” (SAHLINS, 1997b: 132).

A ideia central foi a de focar os atos dos produtores (CERTEAU, 1994), ao invés de seus impactos e reduções. Todos os agentes componentes de um determinado campo estão em contínuo movimento e deslocamento. Tentamos visualizar como as lideranças religiosas Terena se movimentaram no sentido de tornarem-se hegemônicos no campo religioso que engloba suas aldeias e demais áreas indígenas. Ao invés de serem cooptados e acomodados, foram paulatinamente moldando essas instituições e adaptando-as às suas necessidades, conformando o que denominamos de terenização ou indigenização do Cristianismo.

Compreender a gênese social de um campo, e apreender aquilo que faz a necessidade específica da crença que o sustenta, do jogo da linguagem que nele se joga, das coisas materiais e simbólicas em jogo que nele se geram, é explicar, tornar necessário, subtrair ao absurdo do arbitrário e do não motivado os atos dos produtores e as obras por eles produzidas e não, como geralmente se julga, reduzir ou destruir (BOURDIEU, 2003:69).

A tentativa em relação ao campo religioso que se estabeleceu no Sul de Mato Grosso e em Mato Grosso do Sul no século XX envolveu diretamente a etnia Terena. Essa postura ativa dos representantes da etnia nos levou a reafirmar para suas lideranças religiosas as conclusões de Robin Wright e seus colaboradores.

O Cristianismo indígena não é meramente um "verniz" colado sobre uma estrutura preexistente, que existem igrejas e missionários indígenas, e que estes são fenômenos que precisam ser mais bem estudados pela etnologia. Em outros casos, sem dúvida, a natureza da crença é algo a ser aprofundado, mas a superficialidade não deve ser tomada como norma, como muitas vezes acontece, pois isto impede a compreensão adequada das tradições indígenas cristãs (WRIGHT, 1999: 9).

Evidenciar como os Terena alcançaram o patamar de estrategistas, através do viés da religiosidade se fez necessário, pois, inicialmente, se constituíam enquanto consumidores táticos ativos. As lideranças religiosas Terena se movimentaram durante a longa trajetória de agentes táticos para agentes estratégicos, bem como os demais atores com os quais contracenaram enquanto protagonistas (CERTEAU, 1994). A tática inicial foi se colocar no campo religioso. No caso das lideranças da Missão UNIEDAS (MOURA, 2001), fizeram o Seminário e depois assumiram as igrejas como pastores Terena. Em seguida, circularam no campo religioso habilitando-se, constituindo-se e sendo constituídos no jogo da correlação de forças e, paulatinamente, foram se 
instrumentalizando (empowerment) e construindo seu espaço nas aldeias, através das igrejas cristãs, bem como fora delas (MOURA, 2009).

Esse movimento de "consumidores" a "produtores" ganhou proeminência e a individualidade perdeu forças. As pessoas se constituem e são constituídas numa matriz relacional (VIVEIROS DE CASTRO, 2002). A igreja é o resultado de um movimento coletivo liderado por um pastor Terena. Os líderes se constroem e são construídos, ao passo que a instituição religiosa em si os potencializam. São as relações entre os missionários protestantes, os religiosos católicos, os pastores e os leigos Terena, os fazendeiros católicos, os regionais entre outros sujeitos, que os conformam uns aos outros enquanto tais (MOURA, 2009).

De acordo com Moura (2009), podemos (re) afirmar que,

As lideranças religiosas Terena são construtos sociais e, portanto, passíveis de transformação. As agências religiosas, por sua vez, se tornam espaços de poder dessas novas lideranças, moldadas também pelas correlações de forças entre as novas e as antigas lideranças protestantes e católicas. O processo de indigenização do Cristianismo vai muito além da apropriação de bens simbólicos e materiais. Determina um novo lócus de poder, que reflete diretamente no campo político, através do qual os Terena planejam como suas relações políticas internas e externas (MOURA, 2009: 48)

Para Geertz (1989: 83), “(...) a religião modela a ordem social, tal como fazem o ambiente, o poder político, a riqueza, a obrigação jurídica, a afeição pessoal e um sentido de beleza.” É esse caráter modelador da ordem social que buscamos evidenciar a partir dos dados sobre o campo religioso sul mato-grossense, no qual os Terena são agentes em plena interação social (MOURA, 2001; 2009; ISAAC, 2004) . Dentro da ramificação protestante instauram-se as igrejas pentecostais, marcando uma ruptura com o protestantismo histórico, enquanto na ramificação católica as lideranças Terena assumiram as atividades do catolicismo e negociaram dialogicamente com o Xamanismo.

Em sua tese, Moura (2009) compara as motivações dos Terena e de outras populações indígenas Aruak ao se inserir e apropriar-se das instituições religiosas não indígenas, para de alguma forma produzir saídas para uma conjuntura pessimista rumo ao fortalecimento de suas culturas. Evidencia que os Terena enxergam positividade no movimento de apropriação do cristianismo em direção a uma reforma da sociedade. 
A identidade cristã tem o peso de um passaporte para o livre trânsito dentro do arco das novas alianças e interações. Além de harmonizar as relações sócio-políticas no interior e no exterior das novas aldeias, constituiu-se para as igrejas também a meta de levar as boas novas para outras aldeias. Ao mesmo tempo em que queriam aproximar-se amigavelmente dos demais Terena, e de outras etnias indígenas, almejavam também terenizá-los através do Cristianismo Terena (MOURA, 2009: 50).

De uma forma geral, segundo a autora, significam a conversão enquanto uma saída para os indígenas superarem o vício, comportamentos antissociais e fortalecer os laços familiares e as alianças internas e externas.

Isaac (2004) demonstrou que o sistema cosmológico Terena não é fechado às agregações de elementos de outras culturas, assim como qualquer outro aspecto presente na forma de organização dessa sociedade. Agregar o outro a si e transformá-lo em parte constituinte de seu universo cosmológico é característica implícita no Modo de Existir Terena. Nem por isso os indígenas se sentem menos Terena, pelo contrário. Em suas palavras:

Parti da hipótese de que a Sociedade Terena é originária de uma formação histórica recente (menos de três séculos) e sua fonte de origem pode ser definida através de estudos etnológicos e históricos. Durante o processo de sua colonização, a agregação dos elementos estruturais e modelos sociais teriam ocorrido mediante uma filtragem e um redimensionamento, de acordo com os interesses, possibilidades e potencialidades do Grupo. Embora tais agregações tenham se efetivado, elas não foram suficientes para que seus membros rompessem o sentimento de pertencimento à Sociedade Terena. (ISAAC, 2004:1819)

Persistindo nessa mesma ideia, ao final de seu texto Paulo Isaac reafirma que as pessoas são constituídas socialmente e, portanto, expressam-se com base em suas âncoras culturais. As âncoras compõem o Modo de Existir Terena. É por esse motivo que as pessoas exacerbam o seu pertencimento a territórios físicos e simbólicos. Entretanto, as âncoras não são visíveis e tampouco facilmente identificáveis. Elas são manifestadas, principalmente, em momentos de crise, de sofrimento coletivo ou individual. Significou o conceito de transpermanência da crença no "mundo dos espíritos" no momento em que os Terena foram coagidos a deixar uma Fazenda na qual estavam acampados em Rondonópolis-MT, no período em que desenvolvia sua pesquisa. Classificou o momento como particular daquele agrupamento e o materializou a partir do desabafo de uma liderança indígena que se ressentia por não possuir o conhecimento da "Guerra de 
Espíritos". O Terena lamentava-se por todos os Terena que deixaram de atualizar seus conhecimentos ancestrais.

Sabe o que me deixa triste pessoal? Quando eu era criança, lá em Buriti, meu avô contava que a guerra não precisava ser feita com armas. Era feita com o espírito. Se alguém tinha uma contenda com outro, meu avô mesmo fazia isso, pode perguntar pro tio Mário, ele ficava na frente da nossa casa bem quietinho. Contava ele que seu espírito saia do seu corpo e ia até onde estava o seu desafeto para brigar com ele. Era uma briga de espíritos. Era muito mais violenta que essa nossa luta aqui e dava mais resultado. $\mathrm{O}$ inimigo ficava doente, sua vida só ia pra trás e podia até morrer. Nós sabemos fazer guerra de espíritos, mas não tem ninguém aqui em Rondonópolis capaz de fazer isso. Se tivesse alguém, nós não precisávamos estar aqui, sofrendo desse jeito, correndo perigo e colocando a vida das crianças e das mulheres em risco. Bastava a gente se deslocar até o espírito de nossas autoridades e atacá-los e obriga-los a fazer o que nós queremos. Isso é que me deixa triste, a gente não ter aprendido esse jeito de fazer guerra que os nossos antepassados sabiam fazer (Depoimento Terena, 2002. Apud. Isaac, 2004:205).

Foi possível na fala acima perceber a exacerbação do sentimento de pertença xamânica numa situação de particular sofrimento e perdas políticas, sociais e religiosas. A “Guerra de Espíritos” era realizada pelos poderosos xamãs Terena de antigamente. Entretanto, é rememorada como um patrimônio coletivo, uma vez que era usada em favor da harmonia coletiva. O ressentimento, segundo Isaac, também se manifestava porque, apesar de ser um patrimônio da etnia, ali em Rondonópolis não tinha ninguém capaz de realizá-la em favor daquele grupo.

A comunidade estudada por Isaac (2004), majoritariamente crente, não abria espaços para um xamã. Com isso não devemos concluir que os habitantes não se consultavam quando precisavam. Para isso enfrentavam deslocamentos entre o Mato Grosso e o Mato Grosso do Sul, em busca de atendimento espiritual. Os Terena empreendiam, e devem continuar a fazê-lo, as viagens para as Aldeias Cachoeirinha (Miranda-MS), Bananal e Ipegue (Aquidauana-MS) em busca dos xamãs ainda ativos. Isso explica, segundo o autor citado, o fato da fé mudar de direção, naquele momento de crise, de Jesus Cristo para o pajé (xamã). O Cristianismo, por sua vez, começa sendo mediado pelo purutuya (branco no idioma Terena), enquanto o Xamanismo é um espaço "quase interditado" para os não índios (ISAAC, 2004:211). Ou seja, para percebê-lo em campo o pesquisador precisa estar muito atento aos diálogos e relações estabelecidos pelos indígenas em seu cotidiano.

Ambas as matrizes - cristã e xamânica - cumprem papéis diferentes e ao mesmo tempo relevantes para a comunidade, segundo o autor. A partir dessa recente contribuição etnográfica, histórica e sociológica, podemos lançar a hipótese de que o Xamanismo restringe-se mais às 
relações internas, enquanto o Cristianismo revela-se nas relações externas, através do catolicismo e do protestantismo, em suas variadas versões. O binômio civilização/catequese continua fazendo sentido para os Terena. Em suas representações externas, a prudência anuncia que a civilidade aprimorada pelos conhecimentos e vivência cristãos é de grande valia no reconhecimento da alteridade e da irmandade pela sociedade nacional.

Nas duas últimas décadas do século XX, segundo Sahlins (1997a), várias populações indígenas tornaram-se conscientemente avessas às ideologias dos Estados Nacionais, que por muito tempo reproduziram sua subserviência. Apesar de todas as negações à sua emergência, por parte desses Estados, essas culturas se impõem causando desconforto social e político nos espaços nacionais, dentre eles o acadêmico. Segundo nos reafirma o autor em discussão, "devemos prestar alguma atenção aos hesitantes relatos etnográficos sobre povos indígenas que se recusavam tanto a desaparecer quanto a se tornar como nós. (...) Eles vêm tentando incorporar o sistema mundial a uma ordem ainda mais abrangente: seu próprio sistema de mundo" (SAHLINS, 1997a: 52).

Sahlins afirmou ainda que a catástrofe sobre os povos indígenas foi tão intensa que, até recentemente nas décadas de 1970 e 80, quase nenhum estudioso atentava teoricamente para o fenômeno denominado de "intensificação cultural” realçado por Salisbury e Tooker (1984, Apud SAHLINS, 1997a). Somente em 1981 foi organizado o Simpósio sobre "Abundância e Sobrevivência Cultural", no encontro anual da American Ethnological Society, coordenado por Salisbury. Nesse encontro foram apresentados vários estudos de caso, nos quais os povos em destaque enriqueciam sua cultura tradicional ao mesmo tempo, que estavam em franca articulação com o mercado.

Algumas populações indígenas na África interagiam com situações e agentes externos, na dita modernidade, paradoxalmente, sem deixar de se reconhecer Cree, Huron, Tsimshian, Osage e persistiam em sua identificação étnica. Em suas palavras: “Assim, diferenças culturais que a força do Sistema Mundial expulsou pela porta da frente retornam, sorrateiramente, pela porta dos fundos, na forma de uma 'contracultura indígena', um 'espírito de rebelião', ou algum retorno do oprimido do mesmo tipo" (SAHLINS, 1997a: 55).

Abrir-se para novas situações e apropriar-se de suas particularidades não é algo inusitado ao ethos Terena. As elaborações resultantes de situações de perícia entre os Terena, realizadas recentemente por Eremites de Oliveira \& Pereira (2003), Isaac (2004), Azanha (2004) e 
monografias recentes (MOURA, 2001; 2009; VARGAS, 2003; SEIZER, 2017; XIMENES, 2017) destacaram para a etnia características, tais como: habilidade para negociação, diplomacia, hospitalidade, fino trato, cordialidade. Essas características são prerrogativas de um ethos Terena, que vem sendo reformulado e reatualizado ao longo do processo histórico vivido. Podemos, através dos olhos de Hill \& Santos-Granero (2002), perceber a ligação entre o ethos Terena e um possível ethos Aruak.

Nossa leitura está ancorada nos textos dos vários autores contemplados na obra de Hill \& Santos-Granero (2002) "Comparative Arawakan Histories: Rethinking Language Family and Culture Area in Amazonia" e, mais especificamente, nas elaborações de seus organizadores. Estamos considerando o processo de diáspora e conformação de novas alianças em novas terras com novos agentes sociais, uma vez que também percebemos que cada espaço temporalidade produz um campo de poder específico. Feitas estas ressalvas, ainda é necessário salientar que os autores circunstanciados nessa coletânea chegaram à conclusão que mesmo em espaçostemporalidade diferentes, cada um dos povos da família linguística estudada, em diferentes continentes, apresenta características de uma "Arawakan Matrix" e certo ethos Aruak. Esta hipótese seria alicerçada sobre estudos comparativos desenvolvidos em regiões diversas, tal como eram as etnias Aruak focalizadas - Pano, no Peru, Tukano, na Amazônia e Carib na América do Sul.

Assim, ao determinar quais as características da etnia Arawakan, eu examinei situações de influências e trocas culturais interétnicas. Presto atenção principalmente no surgimento do que eu chamo de identidades transetnicas; isto é, grupos que adotam a etnia cultural de outra língua, mas retêm a sua própria língua; ou grupos que adotam uma língua diferente, mas retêm sua etnia. É na fronteira entre povos de diferentes afiliações linguísticas em que podemos observar as diferentes maneiras nas quais a etnia, a língua e a história combinam na negociação da identidade étnica, às vezes, reforçando a existente; e às vezes promovendo a formação de novas identidades (HILL \& SANTOS-GRANERO, 2002:42)

Os autores apontaram a existência de elementos latentes que foram realçados em determinadas situações sugerindo a matriz Aruak, porém salientou que esses não são homogêneos e, portanto, poderiam variar entre os diversos grupos. Matriz para eles tem o sentido de molde ou fôrma, a partir dos quais se constituem os membros da família linguística Aruak; tem também o sentido de network, que liga um grupo a outro mesmo apresentando padrões socioculturais distintos. Ou seja, mesmo habitando regiões diferentes e convivendo com etnias diferentes os grupos afiliados à família linguística Aruak apresentam um ethos comum. Entretanto, essa matriz enquanto produto 
histórico é aberta, desintegrada, incoerente e móvel, funcionando como uma impressão ou estrutura que informa as práticas socioculturais dos membros de uma dada família linguística (HILL \& SANTOS-GRANERO. 2002.42).

As lideranças, apesar de sua idade, vêm se constituindo através de um processo pedagógico de aprimoramento e conformação do perfil do líder Terena. São treinadas para assumir o poder nas aldeias, mesmo as mais jovens. Isto se encaixa tanto para as lideranças temporais como para as religiosas. Suas famílias os ensinam, através da pedagogia do exemplo nas situações cotidianas, como se tornar um líder. A convivência com o poder leva o aprendiz a conformar o perfil ideal.

Muitos líderes políticos mais velhos se empenham em que alguns de seus parentes próximos mais jovens adquiram habilidade na manifestação dos códigos de conduta associados ao exercício da chefia. Para isto, procuram inseri-los gradativamente em funções nas quais possam exercitar atributos já adquiridos e aprender novos conhecimentos. Ao mesmo tempo, ficam de olho em seus concorrentes políticos, pois é importante não perder a oportunidade de evidenciar para a coletividade qualquer desvio de comportamento considerado inadequado. Tanto o empenho na conduta adequada quanto o apontamento de condutas inadequadas parecem desempenhar uma função pedagógica nos processos de instituição e manutenção da liderança. Em sua formação, a liderança vai aprendendo aos poucos a lidar com esse complexo sistema, que exige o acúmulo de vários conhecimentos e habilidades, imprescindíveis para a correta condução dos processos sociais nos quais possa, legitimamente, se apresentar como liderança (PEREIRA, 2009: 83).

Os Terena dirigentes estão sempre atentos às mudanças de conjunturas políticas e seguem adequando e readequando suas condutas de acordo com as novas condições. O ideal Terena é viver em harmonia em suas aldeias, em seus grupos religiosos e parentais, em suas alianças internas e externas. Entretanto, esse ideal não inibe as disputas entre as lideranças estabelecidas e aquelas que desejam se estabelecer.

Anteriormente ao estabelecimento das instituições eclesiásticas católicas e protestantes entre os Terena, os xamãs estavam presentes em todos os níveis de vida dos seus agrupamentos em torno dos troncos velhos. Acompanhavam desde o ritual do nascimento à viagem do espírito, que segundo os Terena é imortal; participavam das caçadas e pescarias, comunicando-se com os donos dos animais e das plantas; curavam os indígenas e os não indígenas de suas enfermidades, através da intermediação com o mundo dos espíritos; causavam as doenças por feitiços; aconselhavam os jovens casais; equilibravam o cosmos através dos rituais de pajelança, nos quais relembravam todos os grandes chefes seus ancestrais; profetizavam e previam o futuro; (SCHADEN, 1976; 
ALTENFELDER SILVA, 1948; OLIVEIRA, 1976; WRIGHT, 1996; CARVALHO, 1996; LANGDON, 1996; ISAAC, 2004; WHITTINGTON, s/d;).

Nas fontes acessadas, os pajés Terena são denominados de Koixomuneti. De acordo com o conceito do Terena Modesto Pereira (1991), “quer dizer 'feiticeiro', alguns traduzem como 'padre', não sei de que maneira a gente pode entender, talvez mesmo como profeta" (PEREIRA, 1991:35). É corrente também o termo médico-feiticeiro, devido à dupla função de curar e por feitiço, segundo as lideranças religiosas cristãs. Em suas viagens ao mundo dos espíritos podiam/podem prever e ver além do alcance dos seus olhos e do tempo presente. Os Terena, ainda hoje, acreditam na imortalidade da alma e na possibilidade de alguns dos seus se comunicarem com os mortos. Ainda hoje, quando os anciãos cristãos relembram seus pajés ficam muito emocionados.

Por exemplo: teve um feiticeiro, ou vamos dizer assim, um curador, ele é tudo na vida, ele é pagé, ele foi morto, na aldeia Cachoeirinha, município de Miranda/MS. Este velho mudou para lá depois de tanto o meu povo persegui-lo, na minha aldeia [Bananal], querendo matar ele. Se você encontra com ele na estrada, num piscar de olho, ele desaparece, transformado num cachorro, num cavalo ou num passarinho, numa onça, tudo isso que para a sociedade civilizada é impossível. Mas isso acontece e aconteceu (PEREIRA, 1991:35).

Independentemente da sua afiliação cristã protestante, Modesto Pereira continuou crendo na existência de pessoas de seu povo que têm o poder de se comunicar com o mundo dos espíritos e dele trazerem as informações necessárias aos demais. Ficou perceptível em sua fala a crença que ainda permeia o seu ser Terena, quando afirmou que isso acontece e aconteceu. Assim como ocorria entre os Taíno, Lokono e Baniwa, segundo SantosGranero, ocorria e ocorre entre os Terena, uma associação entre as lideranças seculares e as religiosas ou, o que atualmente é mais frequente entre os espaços de poder das igrejas (espaço sagrado) e os espaços do cacicado e das representações locais da FUNAI (espaços profanos ou seculares).

De acordo com o exposto acima, podemos afirmar que os Terena continuam, consciente ou inconscientemente, remetendo-se aos elementos da cultura Aruak, embora tenham se deslocado para o interior do Brasil, na América do Sul. Por isso, para compreendermos suas relações internas e externas e sua disposição para apropriar-se de elementos culturais de outras etnias indígenas e não indígenas temos que nos remeter a essa sua afiliação linguística.

A configuração atual dos Terena tem que ser percebida como o resultado de vários séculos de contato com diversas etnias, em diversos espaços temporalidade, das quais foram apreendendo 
elementos materiais e imateriais resultando no que são hoje. Índios Terena cristãos (evangélicos, católicos) e xamânicos; incluídos nos espaços sócio-políticos brasileiros, sejam seculares ou religiosos; índios escolarizados, graduados e pós-graduados, que estão assumindo as negociações de suas demandas; índios aliançados interna e externamente as suas Terras Indígenas; índios guerreiros, que reivindicam a ampliação de suas áreas em litígio.

\section{ALGUMAS CONSIDERAÇÕES}

Tal como John L. Comaroff \& Jean Comaroff (1997) em "Of Revelation and Revolution", observamos o encontro dialético entre o catolicismo, o protestantismo e o xamanismo, enquanto uma história de determinações recíprocas, a partir de um fluxo de trocas. O que para muitos cientistas sociais foi percebido como fenômeno de sincretismo ou de aculturação nós reconhecemos como o resultado de uma situação dialógica entre religiões, se bem que é um diálogo perpassado por relações de poder assimétricas, no qual as lideranças religiosas Terena aprenderam a se organizar, atualizar e atuar ao longo do processo de convivência, iniciado desde o período colonial.

Com isto não pretendemos apagar o débito que o Cristianismo em suas diversas facetas contraiu com as populações indígenas, mas realçar, sem ingenuidade alguma, a capacidade dessas populações de impor-se diante de contextos nos quais as saídas propostas pelos órgãos governamentais foram e são o extermínio ou a aculturação. Muitas populações indígenas conseguiram resistir e retornar a pauta nacional, a partir da promulgação de seus direitos na Constituição de 1988. Direitos esses conquistados a peso de muitos esforços. Todavia, a concretização dessas conquistas continua a ser negociada por lideranças indígenas e pró-indígenas até o presente.

Segundo os Comaroff \& Comaroff (1997:28), os missionários da London Missionary Society, junto aos Tswana, no século XIX, eram desviados constantemente de seus objetivos religiosos, culturais, políticos e sociais pelos africanos e, em contrapartida, os africanos repetidamente se apropriavam, readaptavam e colocavam para os próprios fins dos Tswana do sul da África do Sul, maneiras e meios europeus. Enfatizam que os encontros ao invés de ser um simples exercício entre dominação e resistência “(...) consistiram em um complexo dialético: uma dialética, mediada por 
diferenças sociais e distinções culturais, que transformou tudo e todos da mesma maneira - e reproduziu algumas transformações mais antigas por cima" (COMAROFF \& COMAROFF, 1997:28).

Da mesma forma pensamos os Terena em suas relações com os missionários cristãos. Em nossa análise, ao invés de afirmar que os elementos do Xamanismo Terena se fundem ou se amalgamam aos das religiões cristãs, estamos propondo que coexistem e dialogam entre si, dentro de um campo religioso (MOURA, 2009). Isso pressupõe afirmar que coexistem nas aldeias Terena o xamanismo, o protestantismo e o catolicismo.

Por fim, tivemos a pretensão de apresentar de forma sucinta o debate interno entre as disciplinas de Antropologia e de História ao longo do século passado, bem como o encontro dessas nas três últimas décadas recentes. $\mathrm{O}$ interesse dos estudiosos, que se acreditam vinculados às áreas do conhecimento da antropologia e da história, voltou-se para a interação entre os agrupamentos indígenas e as estruturas sociopolíticas ocidentais, como é o nosso caso. Novas abordagens consideram as dinâmicas locais e globais responsáveis pela trajetória das populações indígenas e as etnias indígenas têm demonstrado que administram e mantêm sua reflexividade sociocultural recorrendo a estratégias políticas e categorias cosmológicas exatamente semelhantes às descritas pelos etnólogos de sociedades 'tradicionais'.

\section{REFERENCIAS}

ALBERT, Bruce \& RAMOS, Alcida Rita (Orgs.). 2002. Pacificando o Branco: Cosmologias do contato no Norte-Amazônico. São Paulo: EDUNESP.

ALTENFELDER SILVA, Fernando. 1948. "Mudança Cultural dos Terena.” Revista do Museu Paulista, São Paulo, v. III (8).

ALMEIDA, Maria Regina Celestino. 2003. Metamorfoses Indígenas: Identidade e cultura nas aldeias coloniais do Rio de Janeiro. Rio de Janeiro, Arquivo Nacional.

AZANHA, Gilberto. 2004. As Terras Indígenas Terena no Mato Grosso do Sul. Brasília, CTI Relatório de Identificação das Terras Indígenas de Cachoeirinha, Buriti e Taunay-Ipegue). (Acessado em www.trabalhoindigenista.org.br)

BOURDIEU, Pierre. 2003. [1998]. O Poder simbólico. Rio de Janeiro, Bertrand Brasil. 
CARVALHO, Fernanda. 1996. Koixomuneti e outros curadores: Xamanismo e práticas de cura entre os Terena. Dissertação de Mestrado em Antropologia Social, Universidade Estadual de São Paulo.

CUNHA, M. C. (org.). 1992. História dos índios no Brasil. São Paulo, Companhia das Letras. Secretaria Municipal de Cultura, FAPESP. (2002). Prefácio. In: ALBERT, B. \& RAMOS, A. R. (Orgs.) (2002). Pacificando o Branco: Cosmologias do contato no Norte-Amazônico. São Paulo, EDUNESP.

CERTEAU, Michel De. 1994. A Invenção do Cotidiano: 1. Artes de fazer. Rio de Janeiro, Vozes.

COMAROFF, Jean, \& COMAROFF, John L. 1993. "Introduction". In Modernity and its malcontents: Ritual and power in postcolonial Africa. COMAROFF, Jean, \& COMAROFF, John L. Chicago, University of Chicago Press.

EREMITES DE OLIVEIRA, Jorge; PEREIRA, Levi Marques. 2003. Perícia antropológica $e$ histórica da área reivindicada pelos Terena para a ampliação dos limites da Terra Indígena Buriti, municípios de Sidrolândia e Dois Irmãos do Buriti, Mato Grosso do Sul, Brasil. Autos $\mathrm{n}^{\circ}$ 2001.60.00.003866-3, $3^{\mathrm{a}}$ vara da $1^{\mathrm{a}}$ subseção judiciária de Mato Grosso do Sul.

FRANCHETTO, Bruna \& HECKENBERGER, Michael (Orgs.). 2001. Os Povos do Alto Xingu: História e Cultura. Rio de Janeiro, Editora UFRJ)

FRANCHETTO, Bruna. 1993. "A Celebração da História nos Discursos Cerimoniais Kuikúro (Alto Xingu).” In: VIVEIROS DE CASTRO \& CUNHA, Manuela Carneiro da (Orgs.). 1993. Amazônia; Etnologia e História Indígena. São Paulo; Núcleo de História Indígena e do Indigenismo da USP; FAPESP. (Série Estudos) pp. 95-116.

Editora S.A.

1989. A Interpretação das Culturas. Rio de Janeiro, Livros Técnicos e Científicos

HILL, Jonathan D. 1996. History, Power, and Identity: Ethnogenesis in the Americas, 1492-1992. Iowa City, University of Iowa Press.

HILL, Jonathan D. \& SANTOS-GRANERO, Fernando (Orgs.). 2002. Comparative Arawakan Histories: Rethinking Language Family and Culture Area in Amazonian. Urbana and Chicago: University of Illinois Press.

ISAAC, Paulo Augusto Mário. 2004. Modo de existir Terena na comunidade multiétnica que vive em Mato Grosso. Dissertação de Mestrado em Ciências Sociais, Pontifícia Universidade Católica de São Paulo).

LANGDON, E. Jean Matteson (Org.). 1996. Xamanismo no Brasil: Novas Perspectivas. Florianópolis, Ed. UFSC.

MONIOT, H. 1988. “A História dos Povos sem História.” In: LE GOFF, J. \& NORA, P. História: Novos Problemas. $3^{\text {a }}$ ed. Rio de Janeiro, Francisco Alves. 
MONTEIRO, John Manuel. 1994. Negros da Terra: índios e bandeirantes nas origens de São Paulo. São Paulo, Companhia das Letras.

MOURA, Noêmia dos S. P. 2001. UNIEDAS: O Símbolo da Apropriação do Protestantismo NorteAmericano pelos Terena Crentes (1972-1993). Dissertação de Mestrado em História. Universidade Federal de Mato Grosso do Sul.

2009. O Processo de Terenização do Cristianismo na Terra Indígena Taunay/Ipegue no Século XX. Tese de Doutorado em Ciências Sociais, Universidade Estadual de Campinas.

OLIVEIRA, Roberto Cardoso de. 1968. Urbanização e Tribalismo: a integração dos índios Terena numa sociedade de classes. Rio de Janeiro, Zahar.

1976. Do Índio ao Bugre: O Processo de Assimilação dos Terena. Rio de Janeiro, Francisco Alves.

PEREIRA, Levi Marques. 2009. Os Terena de Buriti: formas organizacionais, territorialização e representação da identidade étnica. Dourados: UFGD.

PEREIRA, Modesto. 1991. "Depoimento de um líder Terena." In: Revista Terra Indígena, VIII (59).

SAHLINS, Marshall. 1990. Ilhas de história. Trad. Bárbara Sette. Rio de Janeiro, Jorge Zahar.

1997a. O “'Pessimismo Sentimental' e a experiência etnográfica: porque a cultura não é um 'objeto' em via de extinção.” In: MANA. Rio de Janeiro, UFRJ, 3 (1).

1997b. O “'Pessimismo Sentimental' e a experiência etnográfica: porque a cultura não é um 'objeto' em via de extinção.” In: MANA, Rio de Janeiro, UFRJ, 3 (2).

SCHADEN, Egon. 1976. Leituras de Etnologia Brasileira. São Paulo, Nacional, 1976.

SEEGER, Anthony; DA MATTA, Roberto; VIVEIROS DE CASTRO, Eduardo. 1979. "A construção da pessoa nas sociedades indígenas brasileiras". Boletim do Museu Nacional, 32: 2-19.

SEIZER, Antônio Carlos. 2017. Kalivôno Hikó Terenôe: sendo criança indígena terena do século XXI - vivendo e aprendendo nas tramas das tradições, traduções e negociações. Tese de Doutorado em Educação, Universidade Dom Bosco.

LÉVI-STRAUSS, Claude. 1975. Antropologia Estrutural. Trad. De Chaim Samuel Katz e Eginardo Pires, ver. Etnológica de Júlio Cezar Melatti. Rio de Janeiro, Tempo Brasileiro.

TURNER, Terence. 1993. "De Cosmologia a História: resistência, adaptação e consciência Social entre os Kayapó.” In: VIVEIROS DE CASTRO \& CUNHA, Manuela Carneiro da (Orgs.). 1993. Amazônia; Etnologia e História Indígena. São Paulo; Núcleo de História Indígena e do Indigenismo da USP; FAPESP, 1993. [Série Estudos] pp. 43-66.

VARGAS, Vera Lúcia Ferreira. 2003. A construção do território Terena (1870- 1966): Uma sociedade entre a imposição e a opção. Dissertação de Mestrado em História, Universidade Federal do Mato Grosso do Sul. 
VIVEIROS DE CASTRO \& CUNHA, Manuela Carneiro da (Orgs.). 1993. Amazônia; Etnologia e História Indígena. São Paulo; FAPESP.

VIVEIROS DE CASTRO, Eduardo. 2002. A Inconstância da Alma Selvagem e outros ensaios de Antropologia. São Paulo, Cosac \& Naify.

(2): $115-144$.

1996. "Os pronomes cosmológicos e o perspectivismo ameríndio". Mana, Out. 1996. 2

WHITTINGTON, Rev. Harry. s/d. On the Indian Trail in Paraguay and Brazil:The struggles and Triumphs encountered by a Missionary seeking Jewels. Edimburgh, Knox Press.

WOLF, Eric R. 1982. Europe and The People Without History. Berkeley, University of California Press.

WRIGHT, R. M. (Org.). 1996. “Os Guardiões do Cosmos: Pajés e Profetas entre os Baniwa.” In: LANGDON, E. J. M. (Org.). Xamanismo no Brasil: Novas Perspectivas. Florianópolis, Ed. UFSC.

(Org.). 1999. Transformando os deuses: os múltiplos sentidos da conversão entre os povos indígenas no Brasil. Vol. I, Campinas, EDUNICAMP.

(Org.). 2004. Transformando os Deuses: Igrejas Evangélicas, Pentecostais e Neopentecostais entre os Povos Indígena no Brasil. Vol. 2, Campinas, SP: EDUNICAMP.

XIMENES, Lenir Gomes. 2017. A Retomada Terena em Mato Grosso do Sul: Oscilação Pendular entre os Tempos e Espaços de Acomodação em Reservas, Promoção da Invisibilidade Étnica e Despertar Terena. Tese de Doutorado em História, Universidade Federal da Grande Dourados. 